\title{
The Effect of Four Different Approaches to Parent-Child Reading on Young Chinese Children's Reading
}

\author{
Feng Yang \\ School of Education, The University of Nottingham, China \\ E-mail: Yang.Feng@nottingham.edu.cn
}

Received: 08-06- 2016

Accepted: $25-07-2016$

Published: 31-07-2016

doi:10.7575/aiac.ijels.v.4n.3p.47

URL: http://dx.doi.org/10.7575/aiac.ijels.v.4n.3p.47

\begin{abstract}
Forty families with four- to five-year-old Chinese children were chosen as experiment participants and equally divided into four groups for an eight-week parent-child reading experiment in different reading modes. (1) Groups A, B, and C read one of three kinds of Chinese-English audio bilingual picture books respectively: touch reading books, electronic books, and printed books + CDs, 30 minutes per day with their parents in the approach of Early Synchronous Bilingual Reading (ESBR). After the eight-week experiment, children participants cultivated good habits of and interest in reading and their reading comprehension, retelling and expression competence were improved significantly. Performance of each group in weekly reading time and frequency, proportion of recognized Chinese and English words was $\mathrm{A}>\mathrm{B}>\mathrm{C}>>\mathrm{D}$ and differed significantly $(p<0.01)$. The results show that reading bilingualism synchronously is effective and economical, and it not only enhanced children's bilingual competence, but broadened their multicultural international horizon and developed their creative thinking and leadership. (2) Group D kept their original family reading mode and did not progress significantly in reading habits and test indicators $(p$-value $=0.5-1)$. (3) Determinants of reading effect are parents' awareness and choice of reading material, mode, frequency and time. The experiment results suggest that parents can choose bilingual picture books, cultivate their preschool children's reading habits, and develop their children's bilingual reading, listening, and speaking competence through interactive parent-child reading.
\end{abstract}

Keywords: Audio bilingual picture books; early parent-child reading; approach of ESBR; comparative experiment

\section{Introduction}

Early childhood is critical for a child's language development and character formation. Many developed countries and regions attach importance to early childhood bilingual education to cultivate global talents (Yang, 2014). Early language education is an important part of early education and a foundation to study other subjects. It comprises comprehension of listening and speaking and literacy development of native language and foreign language; early childhood reading is one of the main forms in early childhood language education and it can develop children's language, thinking, personality and habit (Zhu, 2009).

Picture book is a window for children to know the world and main material for early childhood reading. Picture book education directly affects the development of children's reading comprehension ability (Wang, 2014). Through reading Chinese and English picture books, children can develop their interest in Chinese and English words, books, reading, and writing, form their good reading habits and skills, and develop their written language (Lian, 2012).

However, $70 \%$ of parents do not realize the significance of early reading (Song, 2013), they suffer from the lack of initiatives and strategies for facilitating early reading (Xi, 2014); 55\% of parents do not know how to choose picture books for their children and what approach can increase their children's reading interest and effects while $40 \%$ of parents do not read with their children (Cai, 2015).

When Chinese parents read with their children, the regular approach is simply reading aloud to children. Children only know the content of story, but do not attend to words, so they may listen to many stories but have no interest in words. This approach is called "regular parents accompanied reading" in this article. When children who cannot recognize words read picture books, they usually attend to pictures only and comprehend stories through guessing, but do not pay attention to words, which is "regular independent reading." These two approaches can only achieve limited reading effects and cannot cultivate children's interest in reading (Zhang, 2008).

Therefore, the study proposes an approach of Early Synchronous Bilingual Reading (ESBR), which encourages parents to choose audio picture books with bilingual recording in standard pronunciation, to read picture books with their children at least 30 minutes per day in the modes of parent-child accompanied reading, audiovisual repeat reading, and role-play reading, and thus to build an economical Chinese and English bilingual quasi-acquisition environment for children in China, to develop their bilingualism in early childhood and improve their bilingual competence and school readiness.

The ESBR approach emphasizes that children can improve their bilingual reading, listening and speaking competence 
through reading picture books word by word and sentence by sentence through role-playing:

1. Goodman's Theory of Whole Language Education (2006), "Language study ought to start from whole to part and children should be allowed to learn listening, speaking, reading, and writing, according to their own needs."

2. Theory of Linguistic Critical Period proposed by Lenneberg (1967), who argued that since children are good in imitating, they can acquire a foreign language easily in an appropriate linguistic environment.

3. Theory of Linguistic Interdependent Development proposed by Cummins (2005), "The linguistic cognitive ability of the mother tongue can transfer to the second language and predict the development of the second language." Early exposure to bilingualism will not delay the development of language and bring confusion to semantic and concept in language. Conversely, early exposure to bilingual language and two cultures can improve the development in both languages and master two cultures (Petitto \& Kovelman, 2003).

The purpose of present study is to introduce the concept and approach of ESBR, show the different effects of different reading materials and approaches, and analyze the determinants of parent-child reading.

\section{Experiment methods}

\subsection{Experiment participants and plan}

The experiment participants were 40 four- to five-year-old children in three middle-class communities in Songshan Lake District, Dongguan City. They were recruited to take part in an eight-week comparative experiment of parent-child reading and were divided into Groups $\mathrm{A}, \mathrm{B}, \mathrm{C}$, and $\mathrm{D}$ with each group was comprised 10 preschoolers. Among them, Groups $\mathrm{A}, \mathrm{B}$, and $\mathrm{C}$ were experimental groups to read touch reading bilingual picture books, electronic bilingual picture books, and traditional printed bilingual picture books with CDs respectively. Group D was a natural comparative group, who kept its original regular family reading mode, which read Chinese printed picture books irregularly.

The criteria for selecting children participants in Groups A, B, and C were four- to five-year-old children who did not learn Chinese and English systematically in early childhood and their proportion of recognized bilingual words and sentences in test materials should be not more than 25\%. Their parents should be willing to spare 20-30 minutes per day to read picture books with them and to use the approach of ESBR in parent-child reading. Parents in Group D were not required to read with their children every day.

Since only ten children were recruited in each group, children who had good performance in bilingualism were not invited to take part in the experiment to avoid the accuracy of comparative data among groups being influenced by the huge gap of a single child's bilingual level. The children who learned or are learning Chinese and English in after-school interestoriented classes would continue to learn them in those classes, so it would be hard to differentiate whether their bilingual and reading competence are improved through reading bilingual picture books or through attending interest-oriented classes. Furthermore, if parents do not have time or are unwilling to adopt the approach of ESBR, the experiment also cannot achieve a satisfactory result. Purposive-sampling was used and which samples are chosen based on who the researcher thinks would be appropriate for the study (Cohen, Manion \& Morrison, 2007). Though the experiment is relatively limited in selecting the site and families, the validity of the approach of ESBR is not affected.

The average gender ratio of children participants in four groups is 1:1 and the average age is 57 months (the youngest is 45 months and the oldest is 69 months). Around $70 \%$ of parents in each group are highly-educated teachers, civil servants and white-collar workers, and 30\% are technicians, who have had secondary vocational or higher education. Among parents who usually accompany their children to read, $80 \%$ are mothers, and $20 \%$ are fathers or grandparents. Parents did not realize the significance of early reading or know effective reading methods.

\subsection{Reading materials}

The main purpose of ESBR is not simply word recognition, but to cultivate children participants' reading habit and improve their bilingual reading comprehension, listening, speaking and expression competence. However, the amount of vocabulary and comprehension and retelling of sentences are still important indicators to evaluate children's bilingual competence.

World Classic Fairy Tale Bilingual Picture Book Series, published by Foreign Language Teaching and Research Press, were chosen as reading materials. They include 10 classic fairy tale books, such as Snow White, Little Red Riding Hood and so on. Each book has around 30 pages, 110 Chinese and English bilingual short dialogues, around 1, 800 common Chinese characters and 900 common English words, bilingual audio narration recorded by Chinese and English broadcasters. The 10 picture books have more than 1,100 Chinese and English sentences, nearly 18,000 Chinese characters and 9,000 English words, but only 400-500 Chinese characters and 200-300 English words are different.

This series of books can be divided into printed version with CDs, electronic version, and touch reading version. The first two versions of picture books cost around $¥ 100$ online, and the third version costs $¥ 130$, but needs a touch reading pen, which costs around $¥ 100$. All materials were bought by The School of Education, The University of Nottingham Ningbo China and presented to participants freely. 
Based on Fry's First 300 Words (Fry, 2000) and List of 406 Common Words in Modern Chinese (Research Team of The Common Words List of Modern Chinese, 2008), 160 most common Chinese and English words (80 Chinese and English words respectively) from picture books were selected for The List of Common Chinese and English Words for Chinese Preschoolers. This list includes categories of numerals, personal pronouns, family members, location words, adverbs, verbs, countries and cities, fruits and foods, household goods and animals. This list was used to test children's mastery of words and phrases of Chinese and English and standard degree of pronunciation. The split-half reliability coefficient for the list is 0.789 .

Furthermore, 20 common Chinese and English bilingual sentences were chosen from ten picture books to form The Testing List of Common Phrases and Sentences in Bilingual Picture Books (split-half reliability coefficient: 0.793). It was used in the pre- and post-experiment test to investigate the mastery level of common sentences in picture books, bilingual reading competence and standard degree of bilingual pronunciation of children participants.

In addition, two pages of a picture book were chosen randomly for each child participant to read Chinese-English bilingual words to check test results.

The self-compiled Record Form of Parent-Child Reading, Questionnaire for Situation of Children's Early Reading in China and Interview Outline for Situation of Family Early Reading in China were used to acquire information about reading experiment. Reliability analyses yielded a Cronbach's alpha of .741 and split-half of 0.716 for the questionnaire.

After test instruments had been compiled, they were sent to representatives of participants for trial to ensure reliability and validity. The representatives are parents from various occupations and their children and the instrument was revised many times based on their suggestions. Participants with different backgrounds were selected in experiment, and they were divided into different groups according to different reading modes. Participant, methodological, and data triangulation were employed in the experiment, and participant triangulation was also adopted in survey of family early reading situation. Qualitative data of field observation and interview supplemented to quantitative data from questionnaire survey. The outcomes of quantitative data analysis were compared with the content of qualitative interviews to add detail and depth to the conclusion of the survey and the experiment for a high reliability.

\subsection{Results}

Table 1 summarizes the three experimental groups' family reading, bilingual reading comprehension, and pre-experiment results. Paired t-test and analysis of variance were used to determine the significance of the differences in indicators.

Table 1. Comparison of Groups A, B, C and D's Pre-experiment Means

\begin{tabular}{|c|c|c|c|c|c|}
\hline Indicators & $\mathrm{A}$ & $\mathrm{B}$ & $\mathrm{C}$ & $\mathrm{D}$ & $p$ \\
\hline Age (months) & 59 & 58 & 56 & 56 & .618 \\
\hline Number of picture books at home (volumes) & 8 & 10 & 9 & 8 & .511 \\
\hline Weekly reading frequency (times) & 2.8 & 3.0 & 3.1 & 3.0 & .887 \\
\hline Time of each reading (minutes) & 13 & 13 & 14 & 13 & .747 \\
\hline Weekly total reading time (minutes) & 42 & 44 & 45 & 42 & .947 \\
\hline Time spent on videos per day (hours) & 3 & 2.9 & 3 & 2.9 & .797 \\
\hline Regular parents accompanied reading (\%) & 47 & 63 & 70 & 62 & .064 \\
\hline Independent reading $(\%)$ & 43 & 27 & 30 & 28 & .151 \\
\hline Non-reading $(\%)$ & 10 & 10 & 0 & 10 & .052 \\
\hline Recognized Chinese words (\%) & 18 & 19.8 & 18.5 & 19.1 & .722 \\
\hline Recognized English words (\%) & 3 & 3 & 4 & 4 & .276 \\
\hline Recognized and comprehended Chinese sentences (\%) & 16.5 & 17.0 & 15.5 & 15.5 & .691 \\
\hline Recognized and comprehended English sentences (\%) & 0 & 0 & 0 & 0 & - \\
\hline Standard degree of Chinese Putonghua pronunciation & $\mathrm{RG}$ & $\mathrm{RG}$ & RG & RG & 1.00 \\
\hline Standard degree of English & $\mathrm{RP}$ & $\mathrm{RP}$ & $\mathrm{RP}$ & $\mathrm{RP}$ & 1.00 \\
\hline Stories retelling in Chinese & $\mathrm{RP}$ & $\mathrm{RP}$ & $\mathrm{RP}$ & $\mathrm{RP}$ & .691 \\
\hline Stories retelling in English & 0 & 0 & 0 & 0 & - \\
\hline
\end{tabular}

Key: $R G=$ relatively good, $R P=$ relatively poor 
Table 2. Comparison of Groups A, B, C and D's Post-experiment Means

\begin{tabular}{|c|c|c|c|c|c|}
\hline Indicators & A & B & $\mathrm{C}$ & $\mathrm{D}$ & $p$ \\
\hline Age (months) & 61 & 60 & 58 & 58 & .732 \\
\hline Number of picture books at home (volumes) & 22 & 25 & 21 & 9 & .081 \\
\hline Weekly reading frequency (times) & 13.2 & 11.5 & 8 & 3 & .063 \\
\hline Time of each reading (minutes) & 28.5 & 27 & 25 & 13 & .000 \\
\hline Weekly total reading time (minutes) & 382.5 & 315.5 & 194 & 43 & .000 \\
\hline Frequency of reading Chinese written words in each picture book & 5.8 & 5.1 & 3.0 & 0 & .000 \\
\hline Frequency of reading English written words in each picture book & 5.3 & 4.5 & 2.6 & 0 & .000 \\
\hline Time spent on TV, computers and mobile phones per day (hours) & 2.5 & 2.9 & 2.7 & 2.9 & .027 \\
\hline Progress compared with pre-experiment test $(\%)$ & -0.5 & 0 & -0.3 & 0 & .323 \\
\hline Regular accompanied reading (\%) & 0 & 0 & 0 & 62 & - \\
\hline ESBR parents accompanied reading (\%) & 67 & 77 & 86 & 0 & .001 \\
\hline Independent reading $(\%)$ & 33 & 23 & 14 & 28 & .001 \\
\hline Non-reading $(\%)$ & 0 & 0 & 0 & 10 & - \\
\hline Recognized Chinese words (\%) & 61 & 54.25 & 46.38 & 19.9 & .002 \\
\hline Progress compared with pre-experiment test (\%) & 43 & 33.5 & 27.88 & 0.75 & .000 \\
\hline Recognized English words (\%) & 32 & 28.13 & 21.25 & 4.5 & .001 \\
\hline Progress compared with pre-experiment test (\%) & 29 & 24.8 & 16.9 & 0.6 & .000 \\
\hline Recognized and comprehended Chinese sentences (\%) & 57 & 52.5 & 44 & 16.5 & .014 \\
\hline Progress compared with pre-experiment test (\%) & 40.5 & 35.5 & 28.5 & 1.0 & .000 \\
\hline Recognized and comprehended English sentences (\%) & 29 & 23.5 & 18.25 & 0 & .008 \\
\hline Progress compared with pre-experiment test (\%) & 29 & 23.5 & 18.25 & 0 & .008 \\
\hline Standard degree of Chinese Putonghua pronunciation & VG & VG & VG & RG & .046 \\
\hline Progress compared with pre-experiment test $(\%)$ & OG & OG & OG & 0 & .051 \\
\hline Standard degree of English & A & A & A & $\mathrm{RP}$ & .046 \\
\hline Progress compared with pre-experiment test $(\%)$ & OG & OG & OG & 0 & .051 \\
\hline Stories retelling in Chinese & RG & RG & RG & $\mathrm{RP}$ & .046 \\
\hline Progress compared with pre-experiment test (\%) & TG & TG & TG & 0 & .024 \\
\hline Stories retelling in English & 0 & 0 & 0 & 0 & - \\
\hline Progress compared with pre-experiment test $(\%)$ & 0 & 0 & 0 & 0 & - \\
\hline
\end{tabular}

Key: $A=$ average, $R G=$ relatively good, $R P=$ relatively poor, $O G=$ one grade, $T G=$ two grades, $V G=$ very good

"The number of picture books at home, weekly family reading frequency, time of each reading and weekly total reading time, average frequency of reading written Chinese/English words in each picture book, and proportion of reading modes" in the above tables show children's changes in reading habits and approaches: each group was roughly equal to each other in the results of the pre-experiment test. They did not have significant difference in age, reading habit and environment, and cognitive competence, which was correlated with selection criteria and group arrangement.

The means of experimental groups differed significantly from Group D in the performance in the post-experiment test, which indicates reading habits and modes of the children participants in Groups A, B, and C changed significantly compared with the pre-experiment test, but Group D did not change.

Table 2 demonstrates that the performance of weekly reading time and frequency and the proportion of recognized and comprehended Chinese and English sentences is $\mathrm{A}>\mathrm{B}>\mathrm{C}>>\mathrm{D}(\mathrm{p}<0.01)$, which shows Groups $\mathrm{A}, \mathrm{B}$ and $\mathrm{C}$ differed significantly, but all of them performed much better than Group D.

The experiment was conducted in winter vacation, children did not go to kindergarten for a month and parents also had a Spring Festival vacation around two weeks. Therefore, some children read with their parents twice or three times per day, especially children participants in Group A and B, who read touch reading and electronic bilingual picture books, had higher reading interest and frequency, more time of independent reading, and better effect. 
"Percent of recognized English/Chinese words, percent of recognized and comprehended Chinese/English sentences, standard degree of Chinese Putonghua/English pronunciation, and stories retelling in Chinese" are used to evaluate children participants' bilingual, reading comprehension and story retelling competence. There were no significant differences among groups in the pre-test performance. However, the post-test results show a significant difference between Groups, A, B, C and D. The means of experimental groups was significantly better than that of Group D, which indicates bilingual, reading comprehension and story retelling competence of children participants in Groups A, B and C achieved a significant progress compared with the pre-test, while Group D did not develop.

"Stories retelling in English" is an indicator to evaluate children participants' English retelling competence. No child participant could retell in English either in the pre- or post-test. The reason is, though children in Chinese environment were exposed to English words, phrases, and sentences in parent-child reading, their daily time to input English was less than 10 minutes, and the experiment only lasted for eight weeks. The limited input was hardly generating an effective output. The reading time and amount of English books need to be increased to improve children's expression competence. Children participants in Group D did not experience English reading, nor start to accumulate input, let alone output.

"Time spent on videos per day" is used to assess children participants' time spent watching TV and using computers and mobile phones. None of the groups exhibited significant change in the post-test: the time spent by children participants in Group A, B and C on videos decreased slightly, while Group D had no change. Children participants in Group B changed the content they watch every day on computers and they read bilingual picture books 30 minutes per day, instead of cartoons. The result suggests that computers, TVs, and mobile phones are different modes of reading in a broad sense in the Internet era, and children participants spend around three hours on electronic media. The situation is similar to the study results of Roberts and Foehr (2008), which indicated that around $60 \%$ of two- to seven-year-old children spend over 2.5 hours watching TV and 3.5 hours, if the exposure to VCRs and computers was included. Through an investigation of 305 children, Zhu (2013) found that children's interest and hobby of TV is formed before six years old, and $46.23 \%$ of children spend more than two hours per day using electronic media equipment. Some parents let their children watch TV in a long time to make them stay quiet so they do not interfere with parents doing housework, which is a harmful action. TV is a motional material; its fast-switch screens make children rarely have enough time to think when they watch TV. Therefore, watching too much TV will impair their development of linguistic competence and communication ability. The most obvious damage is the loss of independent thinking, which will make children unwilling to think initiatively in cognitive study (Yang, 2008).

In contrast, books are stationary reading materials that children can read repeatedly and all of these activities are beneficial for brain development; furthermore, parent-child reading can cultivate children's reading interest and habits and develop their language and cognition (Feng, 2011).

The study also reveals that touch reading picture books are the most convenient and interesting for children. Touch reading picture books increased reading frequency and time, achieved best reading effects among three experimental groups, and became most popular among parents. They can be substituted for adults in accompanying reading to some extent; some parents have even become dependent on them. The research of Han and Zhang (2013) and Yue (2014) also suggested similar results.

When children participants play at the garden of communities every afternoon, many would compete to adapt stories and play roles of stories in picture books and imitate English sentences in stories in an exaggerated tone, such as "Hello! What's your name? Where are you going?", "They are seven dwarfs!" and "He's an ugly duckling!" Many children became leader among playmates and leaded other children to play, which showed bilingual reading broadened their multicultural global horizon and role-play enhanced their bilingual expression competence, confidence, creative ability, and leadership.

Parent participants were all discussing: their children did not like reading books and only wanted to watch cartoons every evening before the experiment, but now they will say "It's story time" to their parents after supper and ask their parents to read picture books, tell story, play roles in picture books with them. In addition, their children try to adapt stories, and make picture books reading become a game that want to play every night. Children can imitate Putonghua and English perfectly and their reading comprehension, retelling, imagining, role-play, expression and story creation and adaption competence are improved significantly.

Compared with English interest-oriented classes, which usually need hundreds of RMB each class and thousands of RMB per year, parents thought the method that buys audio bilingual picture books for parent-child reading, creates a quasiacquisition for English at home, enables children to learn English naturally in role-play is effective and economical. Some parents found that when children read bilingual picture books synchronously, they learned common Chinese words faster and could learn English words with the help of corresponding Chinese words, which is in line with Cummins' Theory of Linguistic Interdependent Development.

Children participants could imitate Putonghua and English very well. Children's reading comprehension, retelling, and imaginative competence, and story creation and adaption were improved significantly compared with the result of the pre-test. Once children's reading habit is formed, they can achieve good results in two months through reading 10 bilingual picture books. If they can continue this reading approach of ESBR, which is "learning through play and play through learning", and read 50 books a year and 100 books in two years, what will be the effectiveness? If this parent- 
child reading can be continued more than one or two years, children's bilingual reading comprehension and oral expression competence will be improved significantly.

\section{Conclusion}

Based on the results reported above, the following conclusions can be made:

1. Though Chinese parents in each group conducted some parent-child reading activities, they did not read every day. Many parents did not realize the significance and necessity of early reading nor an effective method. Therefore, their children did not have a good reading habit or interest and did not perform well in the pronunciation of Putonghua. In addition, their children were insufficient in the knowledge of Chinese vocabulary, were beginners to learn English, and were unsatisfactory in reading comprehension and expression competence. After the eight-week experiment, the number of picture books at home, weekly family reading frequency, time of each reading, and weekly total reading time of children in Groups A, B, and C increased from nine books, three times, 13 minutes and 43 minutes respectively before the experiment to 23 books, 11 times, 27 minutes and 291 minutes respectively. The progress is significant, and the result demonstrates that they have cultivated good reading habits and interest. Their proportion of recognized Chinese and English words and sentences is $54 \%, 27 \%$ and $51 \%$ on average and increased $35 \%$ and $24 \%$ compared with the performance of pretest. Moreover, their standard degree of pronunciation of Putonghua and English also upgraded a level to "Very Good" and "Average", and their story retelling in Chinese become "Relatively Good". Specifically, in eight weeks and 40 reading hours on average, children learned 140-170 Chinese words and 50-70 English words, which shows children learned two or three Chinese words and an English word in each 30-minute parent-child reading on average. Children participants could recognize nearly half of Chinese sentences and a quarter of English sentences in picture books after the experiment. They also have cultivated good habits of and interest in reading and achieved a significant progress in bilingual word recognition and reading comprehension and expression competence. If the factor of forgetting is considered, a post-test immediately after reading each picture book may bring a better performance. However, no child could retell stories in picture books in English in the post-test, which suggests that even children in a Chinese environment read Chinese and English words synchronously, their absorption is not synchronous and the absorption rate is not high. The absorption of English is less than half of that of Chinese. Children can improve their Chinese pronunciation through imitation and repetition in a short time, but it is hard for them to be fluent in English through a short-term reading. To raise the absorption rate of Chinese and English, especially the rate of English, the time and amount of reading bilingual picture books, especially the English picture books, needs to be increased.

2. Children participants in Group D, who did not experience the education intervention of ESBR during the experiment, still read picture books with their parents irregularly. They had no significant progress in the above indicators. The huge gap between the experimental groups and control group shows the effectiveness of ESBR methods.

3. The post-test performance of Groups A, B and C show no obvious correlation with age and gender. Girls are slightly better than boys but the difference is insignificant. Children in white-collar families are higher in the average number of picture books at home, weekly family reading frequency, average frequency of reading each picture book, time of each reading, weekly total reading time, and the performance in the pre- and post-test. The result shows white-collar parents with higher education background have better knowledge of early education and family reading environment, can spend more time accompanying their children to read, and enable their children to achieve a greater reading effect. Bilingual synchronous reading and role-play are economical and effective approaches; they not only can improve children's bilingual competence, but broaden their horizon, and develop their confidence and leadership.

4. Touch reading pens are the most convenient reading tool and most interesting to children, so the average reading time of Group A is twice as much as Group C. Group B read electronic reading on tablet computers, and comes second in reading frequency and time. The ordinary printed picture books + CDs are relatively inconvenient, and Group C, who read them, becomes last in reading frequency, time, and effect. The ratio of the "ESBR" and "independent reading" for Group A, B and C are 7:3, 8:2 and 9:1 respectively, which shows that touch reading and electronic reading mode can reduce children's dependency on listening to parents and enable children to achieve a relatively good effect when the ratio of independent reading is relatively high, but printed books are less attractive and cannot bring good effect even accompanied by parents in reading.

5. Boys and girls have different preferences on stories; girls in the experiment prefer fairy tales, whereas boys like to read the fantasy and adventure stories. Children can read stories repeatedly that interest them but refuse to read uninteresting stories more than once, so choosing picture books they like can increase their frequency of reading to achieve a better reading effect. All children like to watch Chinese cartoons on TV, but no commercially available bilingual picture books are derived from them. If this kind of picture books with vocabulary cards were available, the bilingual reading ability would be better. At present, audio narration of picture books can be repeated only in paragraphs but not word by word and sentence by sentence, and the speed of English narration is too fast for Chinese children who are beginners to learn English. If publishers can enrich picture content, show bilingual word of each item in picture and make words that can be touched to read, print 
in a large font size, add the function of repeating word by word and sentence by sentence, and slow down the speed of English narration. Such audio bilingual picture books can attract Chinese children to read on their own initiative and enhance their bilingual development in entertainment and play.

6. The key determinants of parent-child reading effect include parents' awareness, willingness and action of early reading, selecting reading materials, modes, frequency and time, in particular, creating a family reading environment, choosing and arranging kinds and number of picture books, weekly reading frequency, time of each reading and frequency of reading each picture book. The most important determinant is parents' awareness and willingness of early childhood education and continuous practice of parent-child reading. Parents' willingness and attention to early childhood education and parent-child reading are correlated with their education background: highly-educated white-collar parents are more willing to value the choice of reading materials and approaches, and their children have better reading habit and effect.

\section{References}

Cai, M. (22 May 2015). Internet + Era: Parents Need Make Up the Parent-Child Joint Reading. China Youth, 11.

Cohen, L., Manion, L. \& Morrison, K. (2007). Research Methods in Education (6th ed). London: Routledge.

Cummins, J. (2005). Teaching for Cross-Language Transfer in Dual Language Education: Possibilities and Pitfalls. Paper presented at TESOL Symposium on Dual Language Education: Teaching and Learning Two Languages in the EFL Setting on Bogazici University, Istanbul, Turkey.

Feng, L. (2011). Function of picture books in child-parent reading activities. Research on Library Science, 5(10), 77-79.

Fry, E. B. (2000). Fry's 1000 Instant Words: The Most Common Words for Teaching Reading, Writing and Spelling. Westminster, CA. : Teacher Created Resources.

Goodman, K. (2006). What's Whole in Whole Language? Oakland, CA.: RDR Books.

Han, Y. \& Zhang, W. (2013). Children's early childhood electronic reading in the digital era. Early Education \& Development, 9(1), 13-17.

Lenneberg, E. (1967). The Biological Foundations of Language. New York: John Wiley.

Lian, R. (2012). Application and research of English picture books in preschool English teaching. Journal of Taiyuan City Vocational College, 2(3), 145-148.

Petitto, L. A. \& Kovelman, I. (2003). The Bilingual Paradox: How signing-speaking bilingual children help us to resolve it and teach us about the brain's mechanisms underlying all language acquisition. Learning Languages, 8 (3), 5-18.

Research Team of The Common Words List of Modern Chinese. (2008). List of Modern Common Chinese Words. Beijing: The Commercial Press.

Roberts, D. F. \& Foehr, U. G. (2008). Trends in media use. The Future of Children, 18(1), 11-37.

Song, J. (2013). Investigation and analysis of the current early childhood parent-child picture books reading. Jiangsu Education Research , 20(34), 73-76.

Wang, J. (2014). Thinking about young children's picture book teaching. Read and Write Periodical, 10(02), 33-36.

Xi, L. (2014). Practical study on instructing family parent-child reading. Academy, (22), 53-57.

Yang, D. (2014). Reflection and reconstitution of China's goal of preschool bilingual education. Teli Journal, 9(2), $27-31$.

Yang, H.(2008). Issues caused by watching TV and countermeasures. Current Preschool Education, 20(3), 39-40

Yue, Y. (2014). Influence of Reading Electronic Picture Books to the Reading Ability of at 5-6 Years Old Children (Master's thesis). Zhejiang Sci-Tech University.

Zhang, X. (2008). Effects of Different Reading Modes on Children (doctoral dissertation). Shaanxi Normal University.

Zhu, H. (2009). Language Education of Preschool Children. Beijing: Science Press.

Zhu, Y. (2013). Investigation into 305 electronic media usages of children and youngsters. Chinese Journal of Child Health Care, 16(6), 642-645. 